\title{
Effect of Transplanting Zones and Dates on Pre-imaginal Populations, Parasitism and Attacks of Major Insect Pests of Rice on the Rice-Growing Area of la Vallée du Kou (Bobo-Dioulasso)
}

\author{
Delphine Ouattara ${ }^{1, *}$, Souleymane Nacro ${ }^{2}$, Rémy Dabire ${ }^{1}$, Hervé Bama $^{1}$, Dona Dakouo ${ }^{1}$ \\ ${ }^{1}$ Institut de l'Environnement et de Recherches Agricoles (INERA), Station de Recherche de Farako-Bâ, \\ BP 910 Bobo Dioulasso, Burkina Faso \\ ${ }^{2}$ Institut de l'Environnement et de Recherches Agricoles (INERA), Centre Régional de Formation et de Recherches Environnementales \\ et Agricoles de Kamboinsé, 04 BP 8645 Ouagadougou 04, Burkina Faso
}

Copyright $\subseteq 2018$ by authors, all rights reserved. Authors agree that this article remains permanently open access under the terms of the Creative Commons Attribution License 4.0 International License

\begin{abstract}
Lepidopterous stem borers cause extensive damage in irrigated rice in Burkina Faso and regularly compromise the harvest of the dry season rice in the rice-growing area of la Vallée du Kou in western Burkina Faso. Yield of losses of $40 \%$ were observe during the dry season. The study conducted during the wet season in 2015 examined the effects of areas and of transplanting dates on the evolution of population of stem borer's damage and of parasitism. Rice irrigation area of la Vallée du Kou was divided into three areas within which 12 farmers were selected on the basis of three dates of transplanting rice; they were total 36 for the days three transplanting dates. According to agronomic evaluation, the transplantation dates are influence by the number of tillers and by the number of panicles. The maximum average number of tillers was observed in the second area within the first date of transplantation. Otherwise the second area and the second date recorded the highest number of panicles. Entomological observations were carried on every 7 days from the $21^{\text {th }}$ day to $91^{\text {th }}$ day after rice transplanting in each of the 36 fields. Late transplanting (August) are the most exposed to Orseolia oryzivora attacks. The genus Chilo spp, Maliarpha and Diopsis spp were the most important pests in rice plants on the perimeter of la Vallée $d u$ Kou. Periods of greatest damage were observed in tillering. They were responsible for the deadhearts damage, for white panicles and for the highest rates. These damages were recorded during the first date of rice transplanting. Parasitism associated with the genus Chilo was observed in the first transplanting date. The hectare average yields were most important in the second transplanting date of within the third area. These results on the pre-imaginal populations are important data. These data can be taken into account to improve the development of a strategy to
\end{abstract}

fight against the major insect pests of rice plants. All these elements are linked to the climatic variations.

Keywords Rice Stems Borers, Period of Rice Transplanting, Chilo, Gall Midge, Deadhearts, White Panicles, Pre-imaginal Populations and Parasitism

\section{Introduction}

Rice is a cereal of a great economy and of a social importance in Burkina Faso [1]. In fact, it occupies the fourth rang among grains produced after sorghum, millet and maize [2]. Domestic rice production does not cover the country's needs [1]. To meet the needs of the population, Burkina Faso imports on average 260000 tons of rice per year, more than 30 billion F/CFA of West Africa currency exchange outflow [3].

However, rice cultivation in Burkina Faso is subject to various constraints -- (abiotic: capricious rainfall and low soil fertility), (socio-economic: low equipment of producers), (biotic: diseases, nematodes, weeds, insect pests) -- induce the production of 2 to $38 \%$ depending on the growing season [4].

In Burkina Faso, the main insect pests of rice belong mainly to two orders: Lepidoptera of the family Pyralidae and Noctuidae (the striped borer Chilo zacconius Bleszynski, C. diffusilineus of Joannis, the pink borer Sesamia calamistis Hampson, the white borer Maliarpha separatella Ragonat) and the endophytic Diptera of the Diopsidae family (Diopsis sp) and Cecidomyiidae (Orseolia oryzivora Harris and Gagné) are the main species of economic importance in Burkina Faso [5, 6-7]. 
According to [8] in areas where two to three crops are harvested each year, the first is the most severely attacked, crop losses caused by drillers range from 3 to $95 \%$. Taking into account the data collected during 28 years in India, 1\% of deadhearts or white panicles or both of them caused by lepidopteran entrails $2.5 \%$ to $6,4 \%$ loss yield [9].

The economic importance of lepidopteran stem borers, mainly Chilo zacconius, has been evaluated in the irrigated rice plant of la Vallée du Kou [10-7] in Burkina Faso. Rice stem borers are a recurring problem on the perimeter of $l a$ Vallée du Kou [11]. These insects regularly compromise the harvest in the dry season (January-May) since the 1980 [7-12]. White panicles rates of over $40 \%$ were observed during the 1999 dry season [13]. The yield losses associated with this damage varies from 12 to $25 \%$ (POLASKEK quoted by [13].

Given the intense activity of these drillers and their decisive role in reducing rice yields, it is necessary to adopt control methods to reduce their effects on production. Variation in abundance of rice stem borers is a function of the timing of crop establishment as well as the season and cultural practices (density of transplanting and appropriate fertilization) the work presented in our study falls within this frame

\section{Material and Methods}

\subsection{Materials}

\subsubsection{Study Area}

The Kou Valley is located at $11^{\circ} 22$ 'north and $4^{\circ} 22^{\prime}$ west. The irrigated rice scheme of the Kou valley is part of a vast plain of 9700 ha of area of which 2300 ha are used. The site is currently under used by 1.300 farmers. For the purpose of our study, the rice growing area was divided into three zones:

Table 1. Geographical coordinates of the three study zones.

\begin{tabular}{|c|c|c|c|}
\hline & Zone 1 & Zone 2 & Zone 3 \\
\hline North & $11^{\circ} 22.93^{\prime \prime}$ & $11^{\circ} 22.523^{\prime \prime}$ & $11^{\circ} 23.31^{\prime \prime}$ \\
\hline West & $4^{\circ} 23.527^{\prime \prime}$ & $4^{\circ} 24.154^{\prime \prime}$ & $4^{\circ} 24.76^{\prime \prime}$ \\
\hline
\end{tabular}

Plant Material

The plant material was composed of seven rice varieties used by the farmers. They are NERICA varieties (FKR62N, FKR60N, FKR56N, FKR58N), and 3 Oryza sativa varieties FKR19, FKR14, FKR 52 all from INERA.

\section{Mineral and Manure Fertilization}

Fertilization consisted of manure and mineral fertilizer used by the farmers involved in the study.

\subsection{Method}

\subsubsection{Field Sampling Method}

The fields were chosen according to three transplanting dates of rice. These three dates were repeated in three areas; each transplanting date in 4 fields, making 12 fields per zone, and 36 fields involved for this experimentation.

\section{a) Selection of fields for the first transplanting period}

The selection of the fields for the first date of transplanting was carried out on the field of farmers who transplanted on 13/07/2015. These fields are located in the area $(1,2,3)$. Four farmers were selected for this same date of transplanting per zone considered as first transplanting date.

\section{b) Selection of fields for the second transplanting period}

The choice of farmers for the second date of transplanting was made on the farmers whose transplanting on the 27/07/2015 meaning two weeks after the first date of transplanting. Four fields were also selected in each of the three zones making 12 fields for the second date of transplanting as well.

\section{c) Selection of fields for the third transplanting period}

The third date of transplanting was on 10/08/2015; meaning 2 weeks after the second date of transplanting. Four fields per zone were also selected.

The weekly observation was set to facilitate the comparison comparing the agronomic and entomological parameters according to the dates of transplanting.

\subsubsection{Field Observations}

\section{a) Agronomic observations}

Data were collected from the $14^{\text {th }}$ DAT in the visual observation plots;

- the total number of tillers per hill was recorded;

- the plant height was measured every 14 days out of twenty (20) tillers selected at random in each farmer' plot

- the number of panicles per hill from the heading was also noted $\left(70^{\text {th }}\right.$ DAT).

- At the maturity of rice

Twenty tillers were randomly chosen were harvested at maturity. They were used to evaluate the number of seeds per panicles.

- After the harvest

Fifteen days after harvest, 20 tillers of regrowth of rice were collected from the farmer fields for the same entomological observations of the rice.

\section{b) Entomological observations}

- Visual field observations

Visual observations were made of 20 tillers selected at random on one of the two diagonals of each farmer's plot chosen once a week from the $21^{\text {st }}$ DAT. On each of the twenty tillers, the number of dead cores (during the 
vegetative phase), the number of white panicles (during the reproductive phase) and the number of galls were collected.

\section{c) Entomological observations and sampling on intermediate host plants}

Entomological observations were also made on wild host plants of the genus Oryza longistaminata, Paspalum scrobiculatum and the regrowth of rice.

\subsubsection{Method of Analysis}

The SAS software was used for the statistical analyzes of the data (SAS / STAT, 2010 version 9.2). The analysis was used to test the effect of treatments on the measured variables at the significance level $\mathrm{P}=0.05$

\section{Results and Discussion}

Eleven series of observations were carried out from July to November of that year. For each treatment, the average percentage of gall midge and Lepidoptera damage was calculated and the evolution of the average number of tillers followed. The data for each date has been changed. Values for tiller and panicle evolution have not been transformed.

\subsection{Result}

\subsubsection{Tillering Evolution According to Dates and Zones}

FIG. 1 shows the evolution of tillering as a function of three rice-sowing dates. The production of tillers is initially low (21 DAT), it becomes important at the full tiller stage (42 DAT). At 42 DAT, there is a significant difference between the transplants dates (D1, D2 and D3); for D1, tillering was the most abundant (15.30 tillers) and significantly different from that of D2 with 13.49 tillers / $\mathrm{m} 2$ but was not significantly different from that of D3 (13.09 tillers). The analysis of variance did not reveal a significant difference between the dates for the other 10 series of observations; however, of the 11 sets of observations, D1 showed the highest average number of tillers (15.30 tillers).

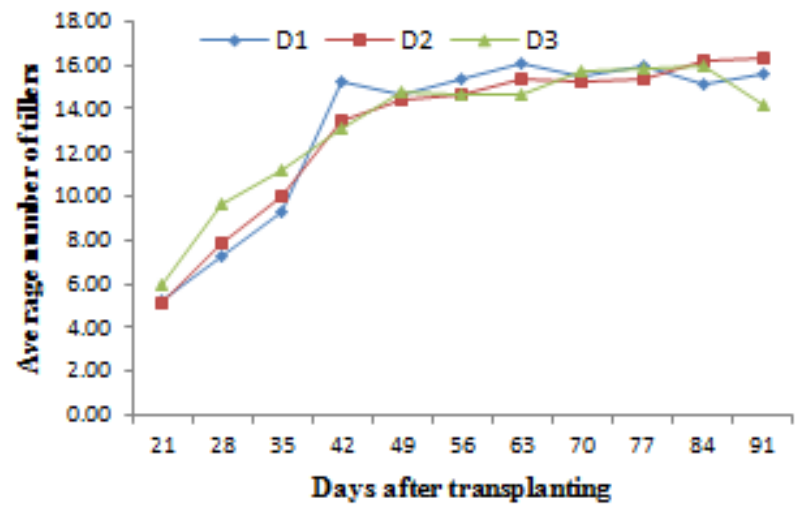

Figure 1. Evolution of the number of tillers according to the dates of transplanting
FIG. 2 shows the evolution of tillering in zones 1, 2 and 3 . The three zones followed the same evolution. At 42 "DAT" zone 1 saw a slight increase in the number of tillers before joining the other zones 2 . Analysis of variance revealed a significant difference between $\mathrm{Z} 1$ and $(\mathrm{Z} 2, \mathrm{Z} 3)$ at the $42^{\text {nd }}$ DAT. In conclusion, zone 1 with respect to zones 2 and 3 has a higher number of tillers.

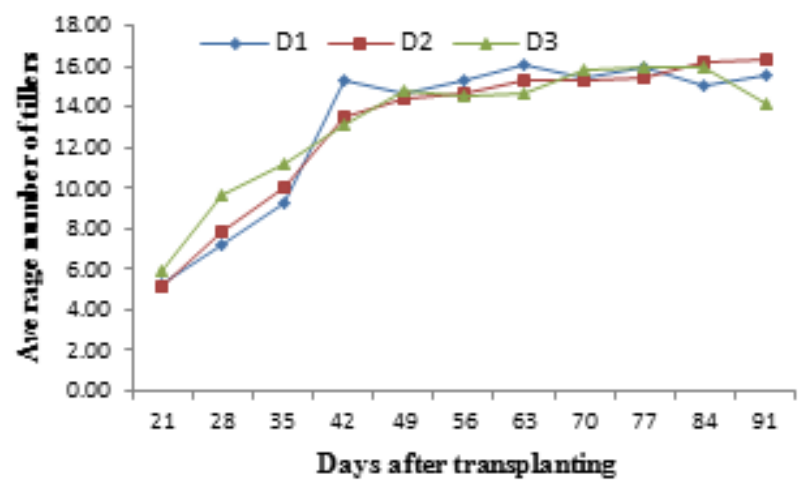

Figure 2. Comparative evolution of rice tillering according to the zones

\subsubsection{Evolution of the Average Rate of Panicles and Panicles White}

\section{- Evolution of the average panicle rate according to the dates of transplanting}

Of the four observation series, panicle occurrence was observed at 70, 77, 84 and 91 "DAT", and it was at the $91^{\text {st }}$ DAT that D1 presented panicles for zone 1. The D2 (15.71 panicle / $\mathrm{m} 2$ ) recorded the greatest number of panicles compared to D1 $(14,50)$. In addition, statistical analysis revealed highly significant differences at $70^{\text {th }}$ and $84^{\text {th }}$ "DAT"s, a significant difference at the $77^{\text {th }}$ (Fig. 3).

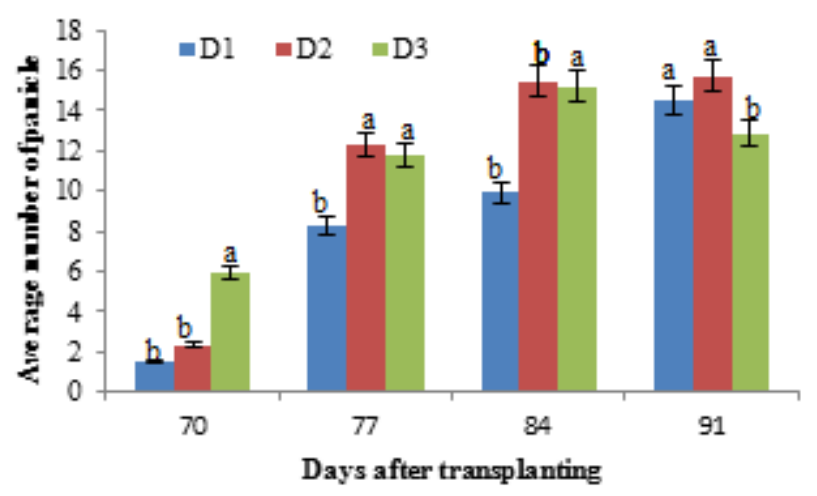

Figure 3. Evolution of number of panicles according to the dates of transplanting.

\section{- Evolution of the number of panicles according to the three zones}

FIG. 4 illustrates the evolution of the average rate of panicles regarding of the three zones. Zone 2 (14.46 panicles) has the highest number of panicles, followed by zone 3 and finally zone 1 . The analysis of variance did not 
indicate a difference between the zones at the $91^{\text {st }}$ DAT; however, there are significant differences between the $70^{\text {th }}$, $77^{\text {th }}$ and $84^{\text {th }}$ DAT zones.

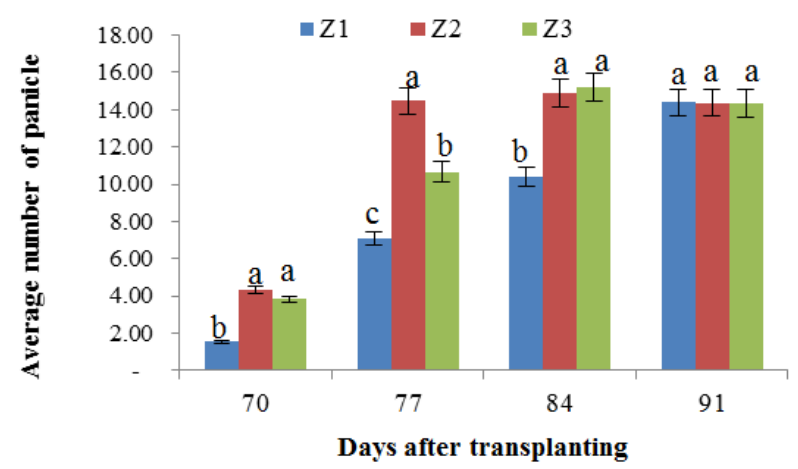

Figure 4. Evolution of mean panicle rate according to the areas.

\section{- Evolution of the number of white panicles according to the transplanting dates}

The $70^{\text {th }}, 77^{\text {th }}, 84 \mathrm{t}^{\mathrm{h}}$ and $91^{\text {st }}$ "DAT" were the periods where the white panicles were noticed. a very significant difference of the number of white panicles was revealed at the 77th and 84th DAT between the dates of transplanting. Of all the series of observations, D2 had the highest rate of white panicles (1.5\%) (Fig. 5).

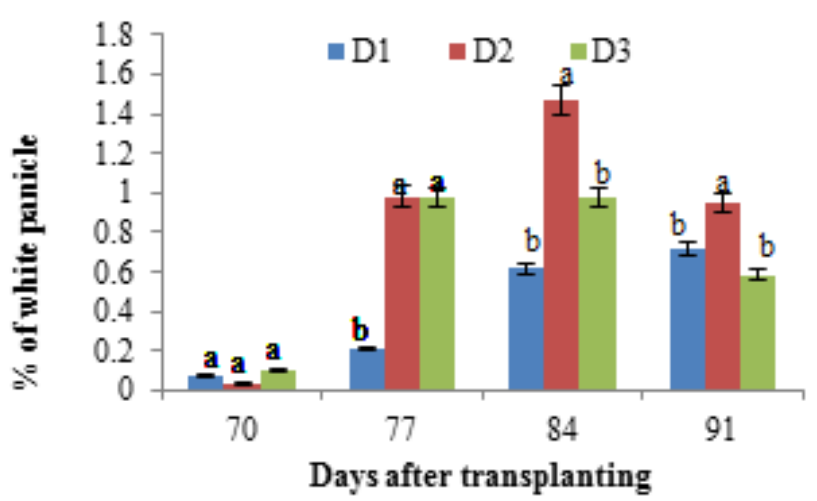

Figure 5. Evolution of average white panicle rate according to the dates of transplanting.

Fig. 6 indicates that Zone 2 had the highest average rate of white panicle, with $1.17 \%$ at the $84^{\text {th }}$ DAT. The analysis of variance revealed highly significant differences between the zones during all the series of observations; zone 3 $(1.13 \%)$ and $2(1.17 \%)$ are very highly significant in zone 1 $(0.08 \%)$.

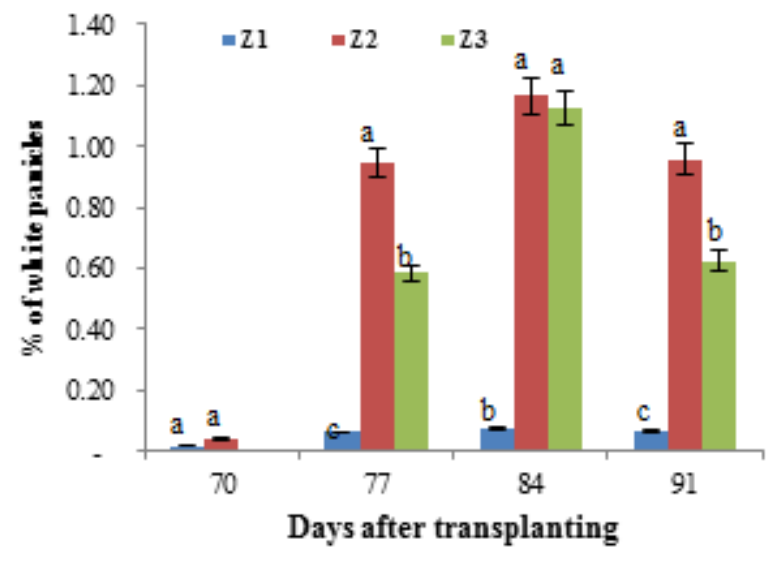

Figure 6. Evolution white panicles according to zones.

\subsubsection{Evolution of Populations}

\section{a-Stem Borer Population}

Fig. 7 shows that D1 recorded the highest infection rate. The infection was observed from the $2^{\text {nd }}$ observation series $\left(28^{\text {th }}\right.$ DAT $)$ to the 10 th observation series $\left(84^{\text {th }}\right.$ DAT $)$. However, no significant differences were detected during the 8 series of observations between the transplant dates $\mathrm{D} 2$ and D3. D1 recorded the highest dead-heart rates $(0.56 \%)$ at $49 \mathrm{DAT}$ and (1.46) at $77 \mathrm{DAT}$. Also at $77^{\text {th }} \mathrm{DAT}$, a peak for all dates of transplanting was recorded.

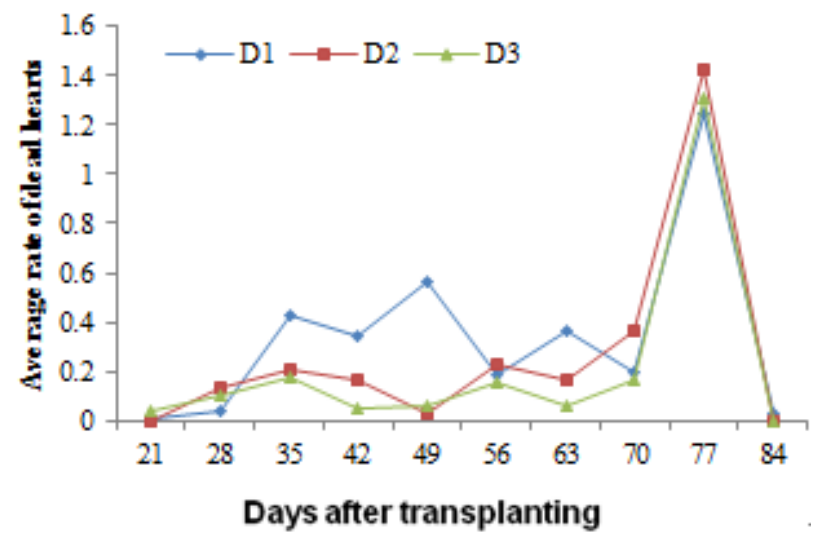

Figure 7. Evolution of the rate of deadheart according to the dates of transplanting

\section{- Stem Borer Population by Area}

Fig. 8 shows a high average rate of deadhearts in Zone 1. The curve is increasing and reaches a maximum at the $49^{\text {th }}$ DAT (4.57\%), decreasing from the $63^{\text {rd }}$ DAT (3.27\%). The other two areas recorded low rates of deadhearts. Zone 2 recorded a rate of (3.70) at the $70^{\text {th }}$ DAT. 


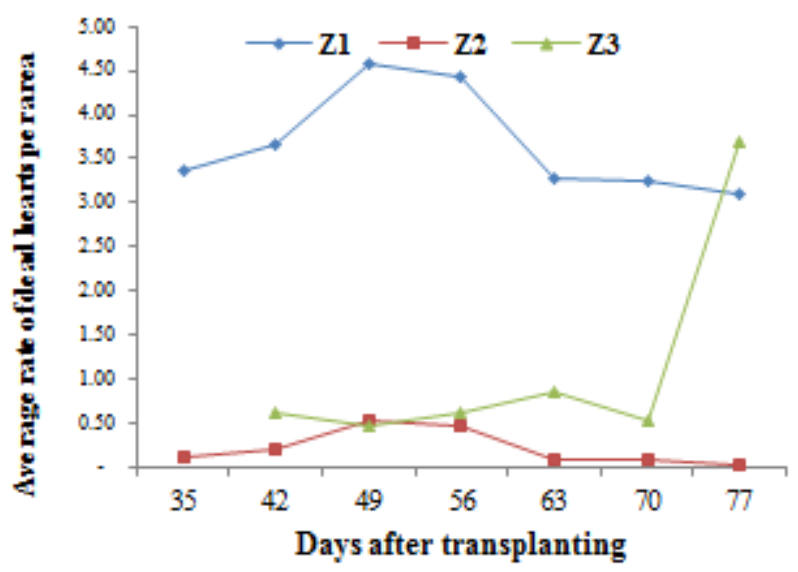

Figure 8. Evolution of the rate of deadhearts according to zones

\section{b-Population of the midge}

In Fig. 9 differences were observed between transplant dates at $49^{\text {th }}, 56^{\text {th }}, 63^{\text {rd }}$, and $70^{\text {th }}$ DAT. Significant differences were observed at 42 and 56 DAT, and highly significant differences observed at 63 DAT. D1 with $2.58 \%$ of galls was not different from D3 (2.41) but highly significant at the $63^{\text {rd }}$ of $\mathrm{D} 2(0.85)(\mathrm{p}=<0.001)$ at the $70^{\text {th }}$ DAT where D2 with $1.12 \%$ and D1 with $0.99 \%$ of galls were different from D3 (1.98\%).

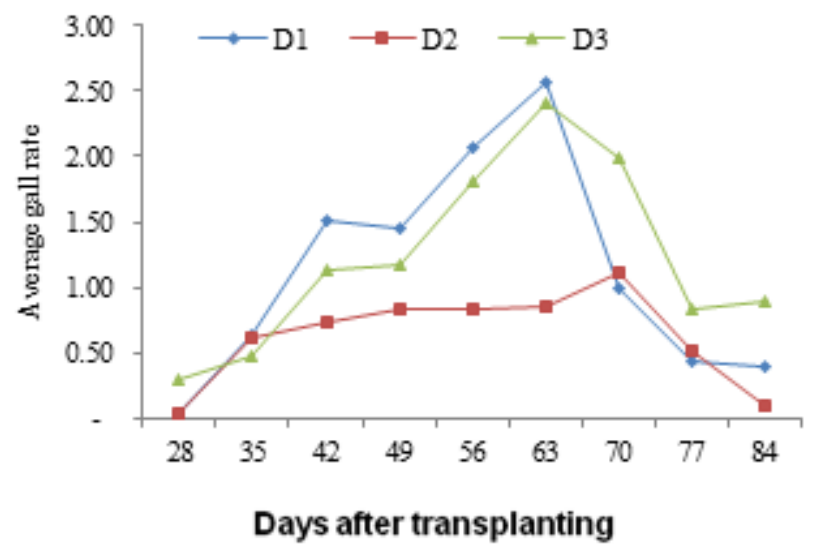

Figure 9. Evolution of average galls midge according to the dates of transplanting

\section{- $\quad$ Population of midge by area}

Fig. 10 shows an almost identical evolution in the 3 areas of gall midge. At 63 DAT, zone 3 recorded the highest gall midge rate $(2.70 \%)$ followed by zone $2(1.93 \%)$ and zone $1(1.20 \%)$.

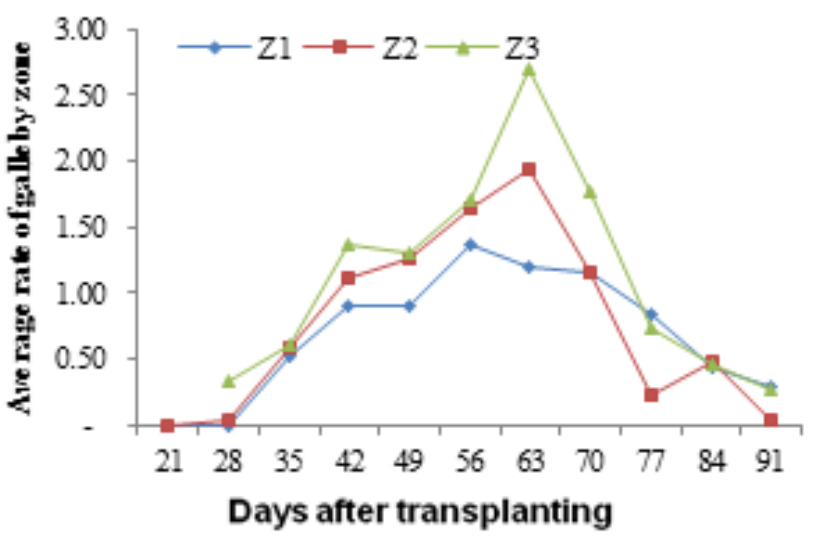

Figure 10. Evolution of galls midge depending on areas

3.1.4. Evolution of the Average Pre-imaginal Population (Larvae + Chrysalis) of Chilo spp. as a Function of the Dates and the Zones of Transplanting

\section{a-Chilo spp}

The analysis of variance revealed a very highly significant difference at the $56^{\text {th }}, 63^{\text {rd }}, 70^{\text {th }}$ and $77^{\text {th }}$ DAT. At 56 DAT, D1 with $7.01 \%$ differed from D3 with $5.33 \%$ and $\mathrm{D} 2$ with $3.5 \%$ pre-imaginal population. At $63 \mathrm{DAT}$ the D1 $(5.35 \%)$ and D3 (4.48\%) are highly different from the D2 (3.08\%). A 70 and 77 th DAT D1 $(6.50 \%$ and $3.93 \%)$ was very highly different from D3 and D2 $(3.89 \%$ and $2.15 \%)$ differs from $\mathrm{D} 2(2.50 \%$ and $2,13 \%)$. A low population of larvae and pupae was obtained at the beginning of the dissections, which progresses between the $56^{\text {th }}$ to the $70^{\text {th }}$ DAT.

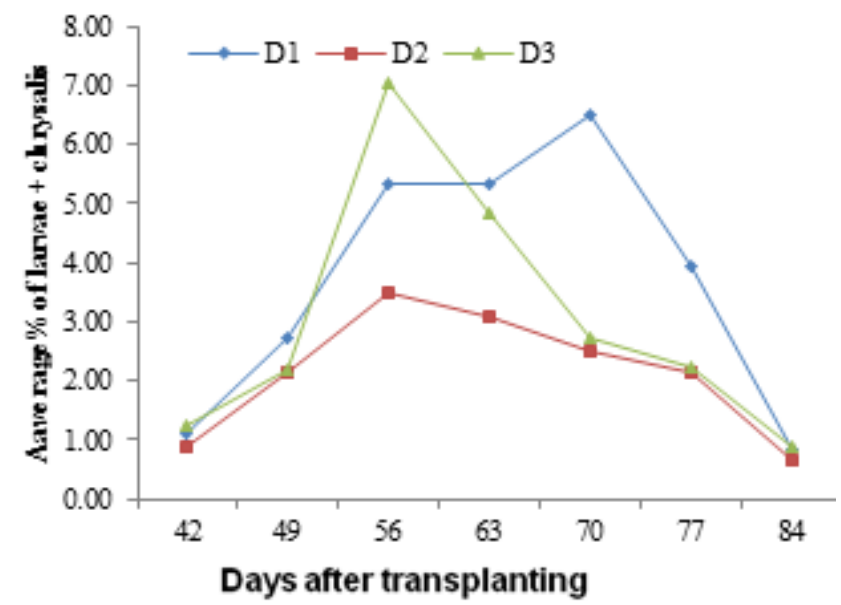

Figure 11. Evolution of the pre-imaginal population (larvae + chrysalises) of Chilo spp. depending on the dates of transplanting 


\section{- Evolution of the pre-imaginal population rate of} Chilo spp. depending on the areas

Fig. 12 shows the degree of attack of pre-imaginal populations in the different zones. Zone 2 seem to have a high pre-imaginal population rate of $7.40 \%$ with a peak in the $77^{\text {th }}$ DAT, followed by Zone $3(7.30 \%)$ and zone 1 $(5.40 \%)$ being the least infested by larvae and pupae.

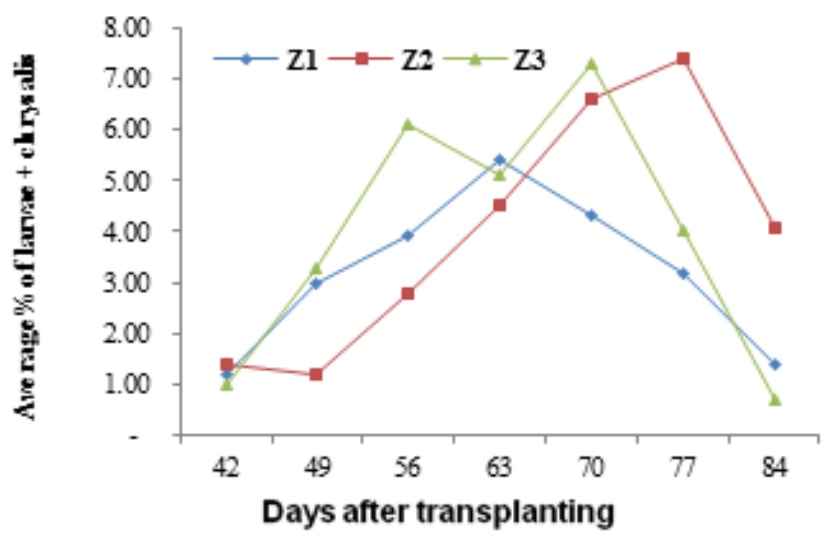

Figure 12. Evolution of the pre-imaginal population (larvae + chrysalises) of Chilo spp. depending on the areas

\section{b-Maliarpha separatella}

The larvae of M. separatella could only be seen from the $49^{\text {th }}$ DAT on the 11 observation series. They were visible on five dissection series for all the dates (Fig. 13). The dissection of the larvae of M. separatella and of Diopsis concerned all the zones. According to the analysis of variance, a difference was observed between the dates at the $56^{\text {th }}$ DAT where D1 with $5.0 \%$ of larvae was statistically different from D2 with $2.0 \%$ and $\mathrm{D} 3$ with $0.1 \%$ of larvae. For the larvae of Diopsis spp., the average calculated rate was zero for all 9 dissection series. Larvae were observed at the 35 th and $4^{\text {2nd }}$ DAT during the vegetative phase of the rice.

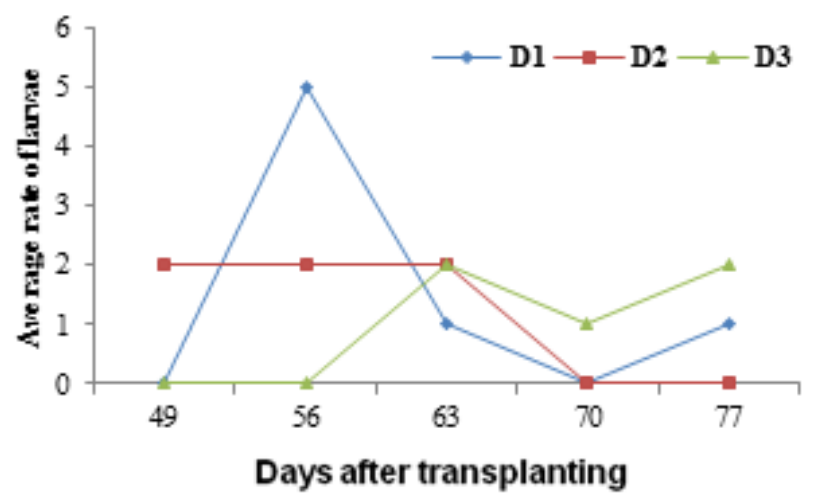

Figure 13. Evolution of the mean rate of larvae of Maliarpha separatella according to the dates of transplanting

\subsubsection{Evolution of the Pre-imaginal Population of the Midge by Dates and Zones}

\section{a-African rice gall midge}

The larval and pupal populations of the midge were recorded from the $35^{\text {th }}$ DAT at a low rate until $84^{\text {th }}$ DAT (Fig. 14). The analysis of variance revealed highly significant differences between the different transplant dates at the $42^{\text {nd }}, 56^{\text {th }}$ and significant DAT at $63^{\text {rd }}$ DAT. At 42 DAT, D3 showed the highest pre-imaginal population (larvae and pupae) (14.53\%), compared with (5.7\%) at D2; the D1 with $6.8 \%$ was not significantly different from D2. At $63^{\text {rd }}$ DAT, D3 with $6.35 \%$ was significantly different from D2 (3.9\%) and D1 (2.4\%) of larvae + pupae. D2 with $0.1 \%$ was the least infested subculture date while D3 with $14.53 \%$ of larvae plus pupae was the most infested.

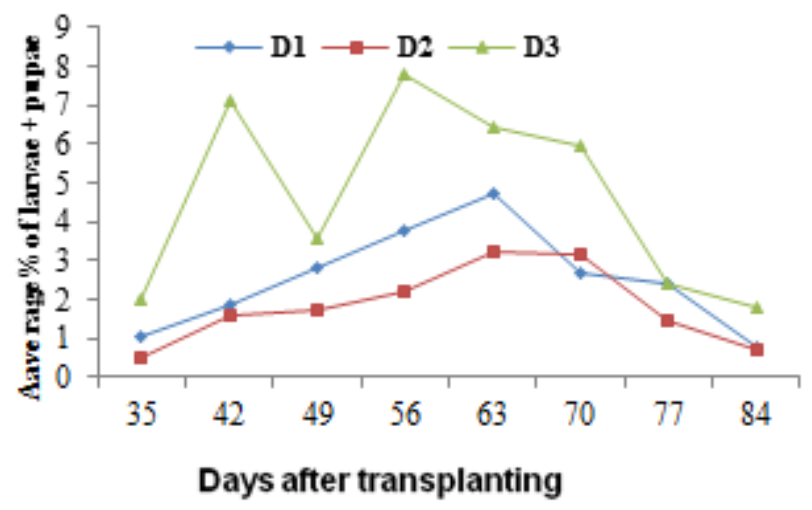

Figure 14. Evolution of the pre-imaginal population of midge according to the dates of transplanting

\section{- Evolution of the average pre-imaginal rate of midge in relation to areas}

Fig. 15 illustrates the evolution of the infections according to the zones and indicates a high rate of gall midge in zone 1 as of the $42^{\text {nd }}$ DAT $(5.97 \%)$. Zone 2 occupies an intermediate position of infection rate after having experienced a low level at the beginning during the vegetative phase. Zone 3 recorded a high rate of infection at the $56^{\text {th }}(5.03 \%)$ DAT

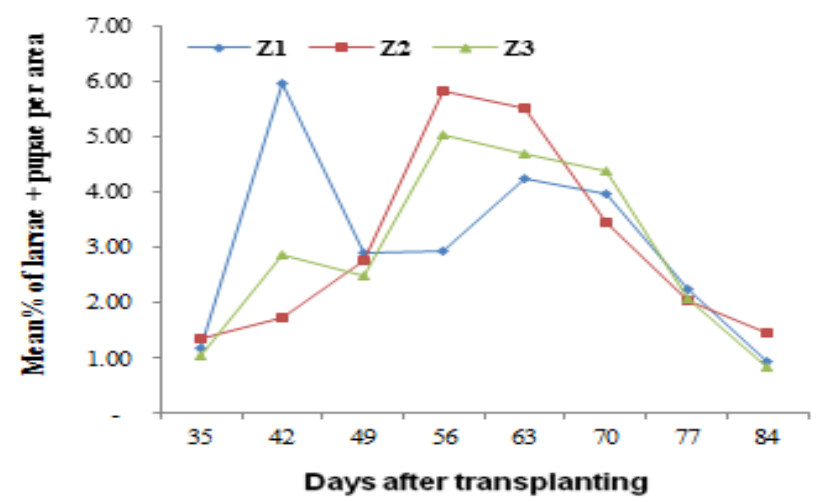

Figure 15. Evolution of the mean pre-imaginal population of midge by dates and zones 


\subsubsection{Parasitism}

\section{a- Parasitism of stem borers}

a1- Evolution of the rate of parasitism affecting the pre-imaginal population (larvae + Chilo spp.)

Chrysalides according to dates and zones

In Fig. 16, the analysis of variance revealed a very highly significant difference at the $56^{\text {th }}, 63^{\text {rd }}$ and $70^{\text {th }}$ DAT and a significant difference at the $77^{\text {th }}$ and $84^{\text {th }}$ DAT. At 56 DAT, D1 and D2 (6.24) \%) were very highly significant different from D3 (4.18\%). At 70 DAT the D1 (6.48\%) was different from the D2 (4.75\%) and the D3 (3.23\%). At 77 and 84 DAT D1 (4.16\% and $2.16 \%)$ and D3 $(3.89 \%$ and $2.15 \%)$ differed from D2 $(2.69 \%$ and $0.71 \%)$. A low population of larvae and pupae were obtained at the beginning of the dissections, which progresses between the $49^{\text {th }}$ and the $70^{\text {th }}$ DAT.

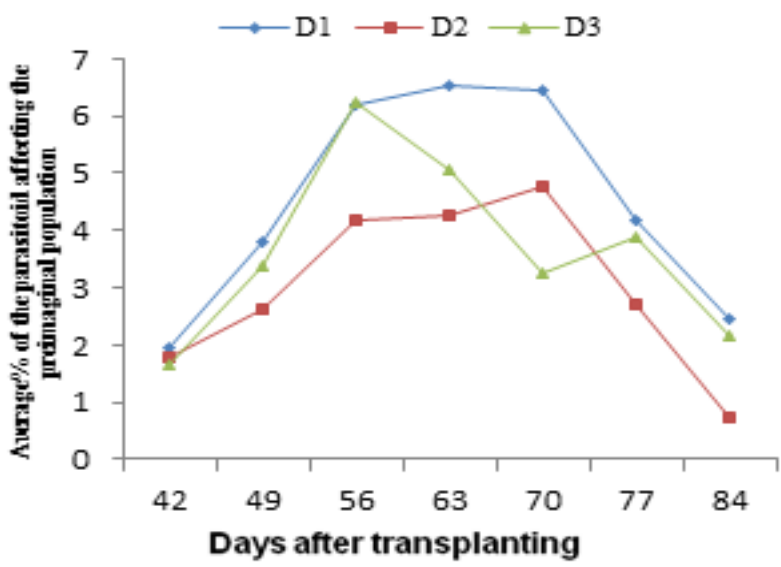

Figure 16. Evolution of parasitism affecting pre-imaginal population (larvae + chrysalides of Chilo spp.), according to the dates of transplanting

- Evolution of the rate of parasitism affecting the pre-imaginal population (larvae + chrysalides of Chilo spp.)

In Fig. 17 the curves indicate the evolution of the pre-imaginal parasitism of Chilo spp. Zone 3 was most favorable to parasitism, with a peak at 70 DAT (5.01). Both zones 1 and 2 have experienced the same evolution, from 56 to $77 \mathrm{DAT}$, the two curves are stable and decreased at 84 DAT.

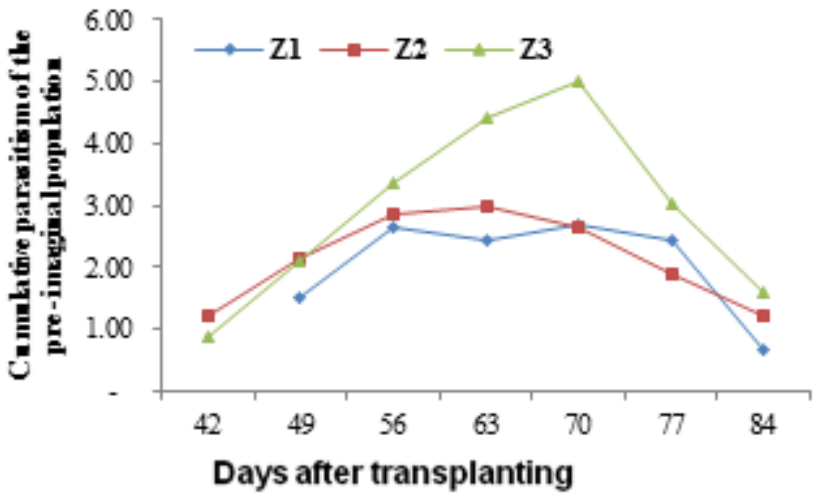

Figure 17. Evolution of cumulative parasitism of pre-imaginal population of Chilo spp. according to dates and zones

a2- Evolution of parasitism against gall midge pre-imaginary larval populations + pupae according to dates and zones

Increasing rates of larval and pupal populations of midge were recorded regarding the transplanting dates (Fig. 18). This increase rates were observed between the $35^{\text {th }}$ and $63^{\text {rd }}$ DAT. A decrease thereafter was observed from the $77^{\text {th }}$ DAT. Analysis of variance revealed a very highly significant difference between D3 and D2 at $56^{\text {th }}, 63^{\text {rd }}$, and $70^{\text {th }}$ DAT. At the $56^{\text {th }}$ DAT, D3 with $8.56 \%$ of parasitism rate differed from D2 (5.21\%) and D1 (5.21\%). At the $63^{\text {rd }}$ and $70^{\text {th }}$ DATs, D3 showed the highest average larval + pupal rate $(11.26 \%)$ and significantly differed from D1 $(7.95 \%)$ and $\mathrm{D} 2(5.05 \%)$.

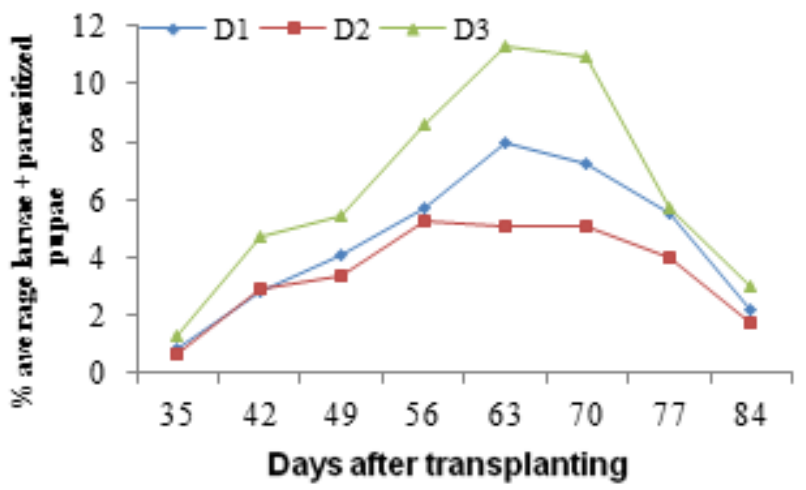

Figure 18. Evolution of parasitism (parasitised larvae + parasitised pupae) of the midge according to the dates 
- Evolution of parasitism affecting the pre-imaginal population (larvae + pupa.), according to the zones and dates

There is no significant difference between the rates of cumulative parasitism of pre-imaginal populations observed between zones. However, zone 3 (8.83\%) recorded a high rate of parasitism at the $70^{\text {th }}$ DAT (Fig. 19).

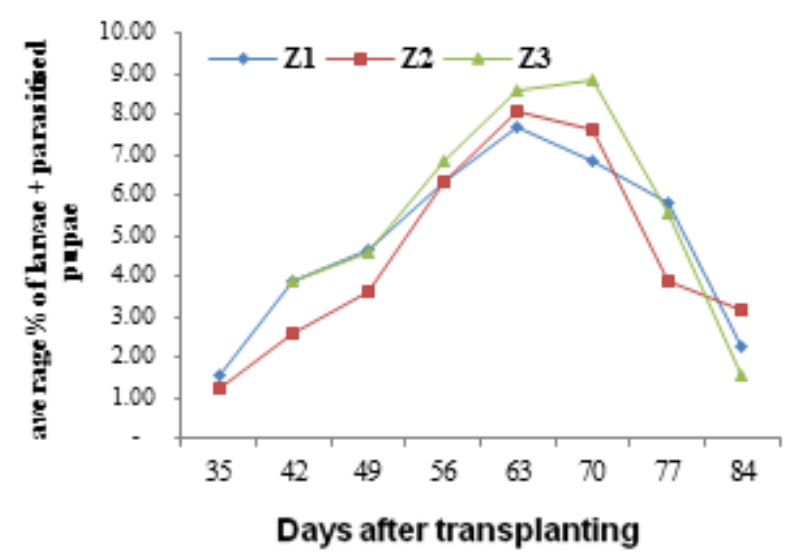

Figure 19. Evolution of parasitism (parasitised larvae + parasitised pupae) of the midge according to the zones

\subsubsection{Evolution of Yield Components and Yield Based on Dates of Transplanting}

\section{a) Yield based on dates of transplanting}

Analysis of variance of the yields recorded did not revealed any significant differences between dates. Table 2 shows that D2 recorded the highest yield in zone 3 with $4.56 \mathrm{t} / \mathrm{ha}$ followed by D1 with $4.51 \mathrm{t} / \mathrm{ha}$ compared with 4.4.6 $\mathrm{t} / \mathrm{ha}$ for D3.

\section{b) Weight of 1000 grains}

In Table 2 the weight of 1000 grains for D1 was the highest (25.88 grams) and D2 (25.82 grams); the lowest weight was obtained at D3 with 25.09 grams. No significant differences were recorded between the dates.

\section{c) Average number of grains per panicle}

The average number of grains per panicle was 148 for D1, 131 for D2 and 159 for D3. No significant differences in treatments were found, however, D3 had the highest average number of grains per panicle, while D2 had the lowest average number of grains per panicle (Table 2).

\section{d) Average grain weight per panicle}

For average grain weight per panicle. D2 (4.11 g) recorded the highest average grain weight per panicle followed by D3 (4.08 g) and D1 (1.31 g). A significant difference was recorded between the dates when D1 differs from the other two dates D3 and D2 in Table 2.

Table 2. Components of yield and yield according to dates and areas of transplanting

\begin{tabular}{|c|c|c|c|c|c|c|c|c|}
\hline \multirow{2}{*}{ Dates } & \multicolumn{2}{|c|}{ Zone 1 } & \multicolumn{2}{c|}{ Zone 2 } & \multicolumn{2}{c|}{ Zone 3 } & \multicolumn{2}{c|}{ Cumul zones } \\
\cline { 2 - 9 } & yield (t/ha) & $\begin{array}{c}\text { weight of } \\
1000 \text { gram }\end{array}$ & yield (t/ha) & $\begin{array}{c}\text { weight of } \\
1000 \text { gram }\end{array}$ & yield (t/ha) & $\begin{array}{c}\text { weight of } \\
1000 \text { gram }\end{array}$ & $\begin{array}{c}\text { weight } \\
\text { panicle / } \\
\text { grams }\end{array}$ & $\begin{array}{c}\text { seed / panicle } \\
\text { number }\end{array}$ \\
\hline D1 & 4.51 & 25.44 & 4.37 & 25.23 & 4.34 & 25.88 & 3.55 & 148 balls \\
\hline D2 & 4.41 & 25.20 & 4.39 & 25.82 & 4.56 & 24.29 & 4.11 & 131 balls \\
\hline D3 & 4.46 & 25.09 & 4.41 & 25.39 & 4.37 & 25.37 & 4.08 & 159 balls \\
\hline Proba & 0.767 & 0.699 & 0.989 & 0.851 & 0.477 & 0.086 & - & - \\
\hline Meaning & NS & NS & NS & NS & NS & NS & - & - \\
\hline
\end{tabular}




\subsubsection{Results of Observations on Intermediate Hosts}

Wild rice (Oryza longistaminata), the weed Paspalum scrobiculatum, and the regrowth rice were recognized as alternative host plants for rice stem borers and rice gall midge. In our study, four series of observations on these weeds and the regrowths rice allowed us to follow the evolution of the damage as well as the pre-imaginal populations that they sheltered after the rice harvesting. These observations were made 15 days after harvest and once a week for one month.

\section{a) Evolution of the gall rate on the regrowth's rice, Oryza longistaminata, and the genus Paspalum scrobiculatum}

The gall levels observed in the Paspalum genus (3.3\%) were very low compared to those observed in wild rice $(6 \%)$. On the contrary, those observed on regrowth of rice $(6.6 \%)$ were higher to the first two. Fig. 20 shows that galls were observed on regrowth of rice and wild rice from the first observation series two weeks after harvest, as for the genus Paspalum, they were encountered in the second observation series. The statistical analysis recorded a difference between the intermediate hosts as early as the third series of observations.

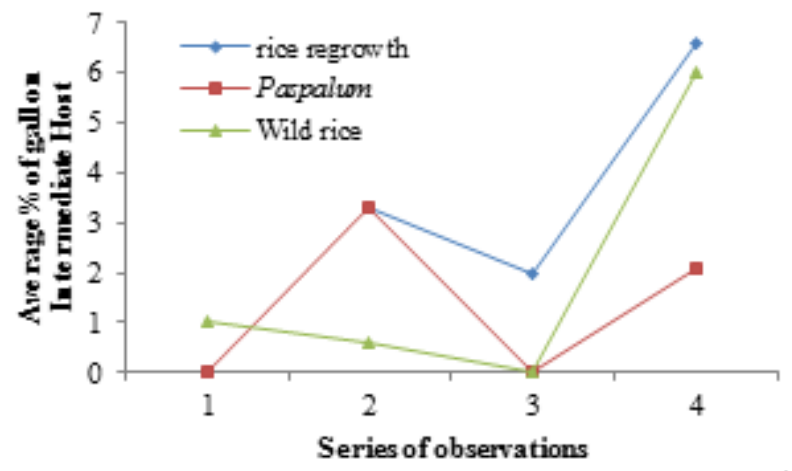

Figure 20. Evolution of the average gall midge rate on the regrowth rice, Oryza longistaminata, and Paspalum scrobiculatum after harvesting rice at la vallée du kou, Burkina Faso

\section{b) Evolution of deadheart on regrowth of rice, Oryza longistaminata, and genus Paspalum scrobiculatum}

In contrast to galls, higher rates of deadheart were observed on regrowth of rice $(5.5 \%)$ and $O$. longsitaminata (6.0) from the third observation series. Fig. 21 shows an increase in the rate of deadhearts from the $1^{\text {st }}$ to the $3^{\text {rd }}$ date of observation. The analysis of variance revealed significant differences in the second and fourth series of observations.

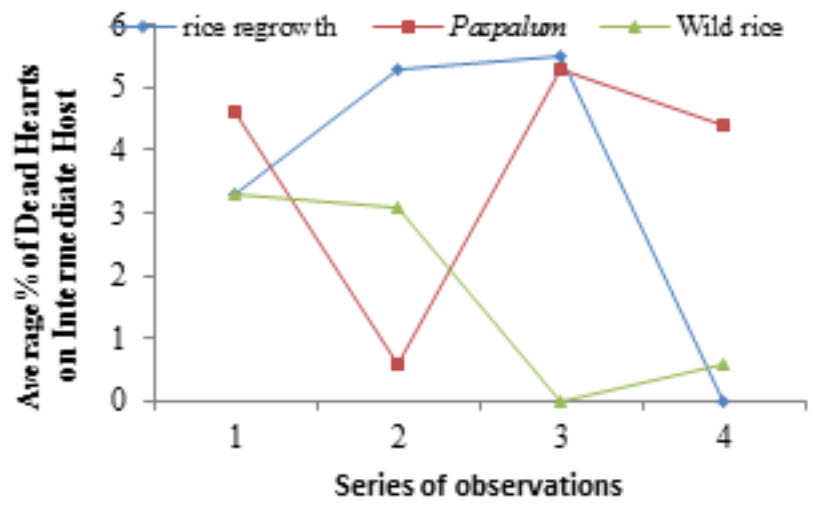

Figure 21. Evolution of the average rate of deadhearts on the regrowth rice, Oryza longistaminata, and Paspalum scrobiculatum after harvesting rice on the rice perimeter of la Vallée du Kou, Burkina Faso

\subsubsection{Evolution of Pre-imaginal Populations on the Regrowth Rice, Oryza longistaminata, and Paspalum scrobiculatum}

\section{a) Cumulative evolution of the pre-imaginal population (larvae + pupae) of the rice midge}

The presence of $O$. oryzivora larvae and pupae was very low and negligible in the different series of observations made in wild rice stems and in rice regrowth. Rates have ranged from 0.3 to $0.6 \%$. The regrowth rice recorded the highest rate $(1.3 \%)$ of pre-imaginal population. This level was 0.5 on P. scrobiculatum. Analysis of variance revealed a highly significant difference between the regrowth rice, $P$. scrobiculatum and $O$. longistaminata in the $3^{\text {rd }}$ observation series (Fig. 22).

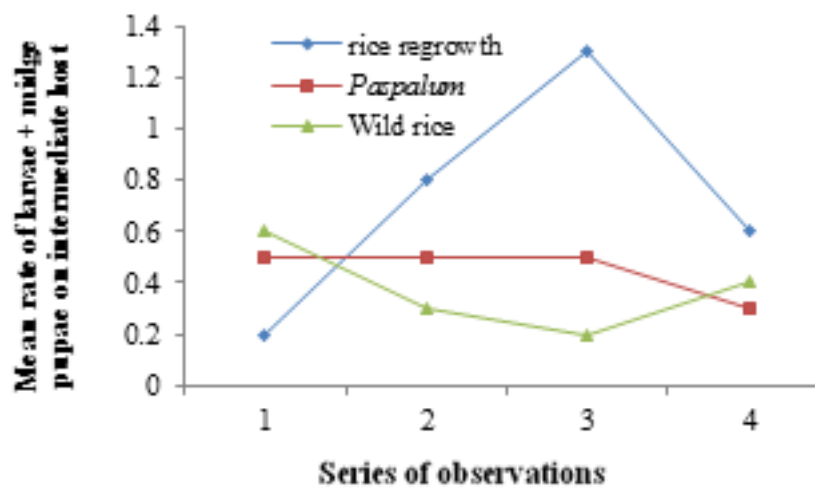

Figure 22. Evolution of larval and African gall midge pupae on the regrowth rice, Oryza longistaminata, and Paspalum scrobiculatum after rice harvesting on the irrigated scheme of Vallée du Kou, Burkina Faso 


\section{b) Evolution of the cumulative parasitism affecting the pre-imaginal populations (larvae + pupae) of the rice midge}

Parasitism affecting the larvae and pupae of Orseolia bonzii was present on P. scrobiculatum in the series of observations at a low rate (from 0.2 to $0.5 \%$ ). On the other hand, the presence of larvae and pupae was observed at higher rates on regrowth of rice (3 to $0.9 \%$ ); for wild rice, an average rate of larvae and pupae was greater $(0.7$ to $2 \%)$ than that observed on $P$. scrobiculatum. The analysis of variance revealed a significant difference between the intermediate hosts in the $3^{\text {rd }}$ observation series. The evolution of parasitism indicates that the maximum level was $0.9 \%$ for the regrowth of rice in the 3 rd series, $0.4 \%$ for $O$. longistaminata and P. scrobiculatum during the $4^{\text {th }}$ observation series (Fig. 23).

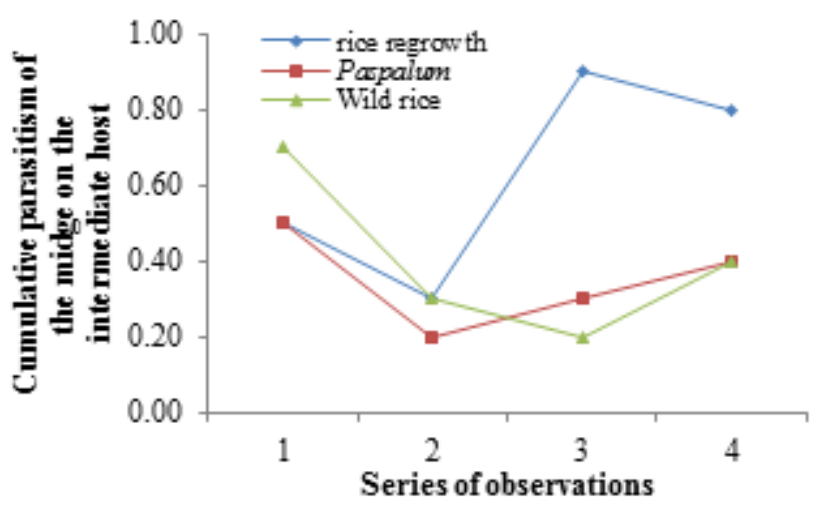

Figure 23. Evolution of cumulative parasitism (larvae + pupae) of rice gall midge on the regrowth rice, Oryza longistaminata, and Paspalum scrobiculatum after harvesting rice on the irrigated scheme of la vallée $d u$ kou, Burkina Faso

3.1.10. Evolution of the Average Larval Rate of Chilo spp. on the Regrowth Rice, Oryza longistaminata, and Paspalum scrobiculatum

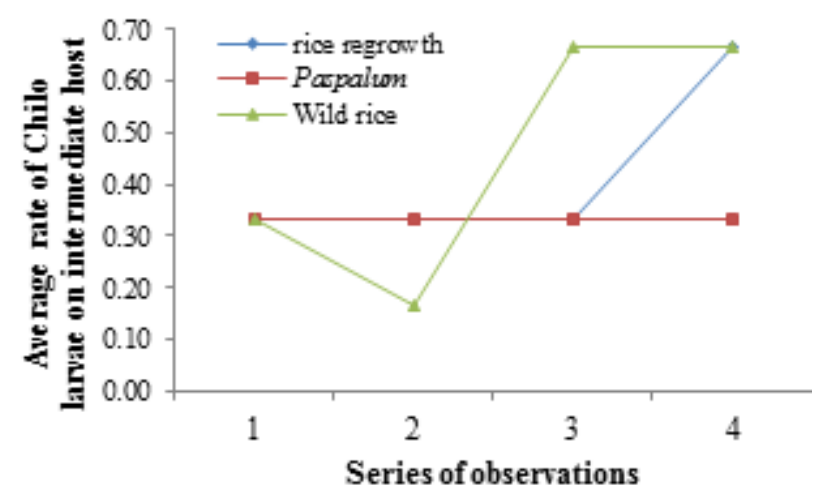

Figure 24. Evolution of the average larval rate of Chilo spp. on the regrowth rice, Oryza longistaminata, and Paspalum scrobiculatum after harvesting rice on the rice perimeter of la Vallée du Kou, Burkina Faso

The study revealed the presence of Chilo spp larvae during the four series of observations. The highest larval levels $(0.7 \%)$ were observed on $O$. longistaminata and regrowth of rice with $0.3 \% P$. scrobiculatum larvae recorded the lowest rate (Fig. 24). According to the analysis of variance, a significant difference was observed between the regrowth rice and $O$. longistaminata in the $3^{\text {rd }}$ observation series. The rate of larvae observed on $P$. scrobiculatum did not evolve during the 4 series of observations.

\subsection{Discussion}

In the light of the results on the effects, from the zones and of the dates of transplanting, on the pre-imaginal populations and assessment of the incidence of attacks, on the major pests and associated parasitism depending on three periods of rice transplantation, we can state that the original objective has been confirmed.

The study of the agronomic parameters allowed us to reach the different results, which are the evolution of the tillering of the rice plants, the dynamics of the pre-imaginal populations of the drillers of stems and the African midge of the rice plants. The evolutions of parasitism affected populations of larvae and pupae and as well as the evaluation of yield components and yield according to areas and dates of transplanting. The areas and dates of transplanting influenced the number of tillers and the number of panicles. The maximum average number of tillers obtained during the study was observed in the second zone of the first date of transplanting. However, it is the second date of the second zone that has collected the largest number of panicles. According to [14], all potential tillers do not grow up, where as some remain dormant when environmental conditions are unfavorable or difficult. Results on the maximum tillering period confirm above quoted results from [13, 15-11]; CHAND and ACHARYA quoted by [11], who located tillering at the $56^{\text {th }}$ DAT, taking into account the duration of the tree nursery.

The damage caused by rice plants midge has varied according to the areas and the dates of transplanting. The maximum average galls were observed at $63^{\text {rd }}$ DAT in the third zone and the third date of transplanting as well. The late transplanting periods, in August, that whose most exposed to Orseolia oryzivora attacks, well as the transplanting fields July was not affected. These high infestation levels of the third transplanting date seemed to be linked to the late transplanting period. In fact, infestations increased from the beginning of the cycle (28 DAT) to (63 DAT) and then decreased in relation to the abundant production of tillers and parasitism. The evolution of the infestations seemed to follow that of tillering. The staggering of the crop on the perimeter favored the multiplication of the number of midge generations by providing successive habitats. This habitat allowed the populations to reproduce throughout the cultural season with more damage on the fields transplanted late [16]. In these studies, attacks of the 
African rice-midge were highest in transplanted rice plant fields at the end of August 2015, to compare with those transplanted on $13^{\text {th }}$ and $27^{\text {th }}$ July. The weak midge attacks on all observations made on the perimeter during 2015 wet season would seem to be linked to a good mastery of the technical itinerary and the training of Producers in Integrated Management of Production and Depredators (GIPD). The field of participatory training is given to rice farmers of school fields in Burkina Faso by and large and Vallée du Kou in particular.

The damage of lepidopteran stem borers, which causes deadhearts and white panicles, was lower in 2015 wet season to compare with other dry seasons. The damage of these main borer insects was greater in the fields of the first periods of transplanting than in the $2^{\text {nd }}$ and $3^{\text {rd }}$ period. The study found that early dates recorded the highest rate of deadhearts and white panicles. The maximum rate of white panicles obtained during this 2015 wet season has been beyond the intervention threshold reported by [17]. Were as my study pointed out $1.7 \%$ of white panicles, the author of the [17] found out in is study $1 \%$ of the same product.

Lepidoptera mainly Chilo spp. and midge also finds refuge in relay host plants. These host plants are constituted by regrowth of cultivated rice, wild rice (Oryza longitaminata) and wild grass (Paspalum scrobiculatum). Parasitism of the pre-imaginal population of Chilo spp. on these host relay plants, particularly on Oryzae longistaminata, Paspalum scrobiculatum and rice regrowth, are important data that can be exploited for biological control purpose. It requires a precise identification of the parasitoids observed on the perimeter. According to the authors [13,18-19], O. longistaminata plays an important relay plant role for the survival of rice midge in the absence of cultivated rice. In view of these results, lepidopteran stem borers, mainly the genus Chilo spp., also find shelter within these intermediate host plants. Moreover, the rates of cumulative parasitism observed on the pre-imaginal Chilo spp. populations (larvae and chrysalises) testifies to the action of natural enemies on the pre-imaginal populations of these insects within the intermediate host plants.

As the whole parasitism on the pre-imaginal population of the rice midge was important. Parasitoids associated with rice midge have been observed late in rice fields in $l a$ Vallée du kou. It was the late transplanting periods (August) that were more exposed to Orseolia oryzivora attacks than to the transplanted fields in July. Parasitism pre-imaginal on the genus Chilo was more important at the vegetative stage than on the first date of transplanting. On the other hand, for the midge, parasitism has been more important on the last transplanting dates, however stem borers has been more important at the first transplanting dates. Our results are similar to those reported by [12-4], who obtained result of high parasitism rates of African rice midge in the south-west of the country. These authors report that parasitism affecting rice midge occurs late in the season after the damage has taken place. Larval and nymphal parasitism has a close relationship with the degree of midge attack.

By considering the yield components and the yields itself, it is the second transplanting date, and the third zone that records the highest yield. The critical role of lepidopteran and the stem borers and rice midge in the yields reduction were highlighted in our study, although they are not the only ones responsible for this loss in rice yield. The yield of a crop also depends on several biotic and abiotic factors. Authors such as [20, 17, 21, 15-22] have reported the importance of early transplantation on yield. The hypothesis that may explain the given yields may be partly linked to the dates of transplanting but also to crop areas and to attacks and parasitism on the pre-imaginary population of stem borers as well. [5] estimates that the yield of rice and its components are widely influenced by the infestation leading to low panicle numbers, and also to an average weight of 1000 grains and consequently to a loss of yield and low yield.

\section{Conclusions and Recommendations}

Works carried out during the 2015 wetland campaign, on the irrigated rice perimeter of la Vallée du Kou, aimed at studying the effect of zones and dates of rice plant transplanting. Parasitism and level of damage of main insect pests; and were targeted. In order to assess the impact of three transplanting dates on the level of damage and parasitism associated with pre-imaginal populations we have decided to explore ways and means to help producers mitigate the effects. The study of the agronomic parameters allowed us to obtain different results. Transplanting zones and dates influenced the number of tillers and of panicles as well. The mean number of tillers obtained in this study was observed at the second zone and the first date of transplanting. However, it is the second zone and the second date that have the highest number of panicles.

Maximum gall midge was observed at the $63^{\text {rd }}$ DAT on the third zone and the third transplanting date. Rice plants transplanted late (August) were the most exposed to Orseolia oryzivora than early transplanted (in July) ones.

Parasitoids associated with rice gall midge were observed late. Parasitism, pre-imaginal on the genus Chilo was more important at the vegetative stage.

Considering the yield components and yields, it was the second transplant date, the third area that recorded the highest yield. The key role of stem borer lepidopteran and rice gall midge in reducing yields was highlighted during our study, although they were not solely responsible for this loss of rice yield. The yield of a crop also depends on several biotic and abiotic factors.

In the light of the results obtained, the following recommendations may be considered: 
It should be noted first of all the influence of early transplanting and their regrouping in the management of the African rice midge on the rice irrigated scheme of la Vallée du Kou but such an approach requires a good awareness of the farmers of the plain.

Awareness should be raised on the following aspects:

- the grouping of the transplanting dates on the entire rice plain;

- early transplanting in July;

- the destruction of volunteer plants and alternative hosts.

These farming practices can limit the economic impact of major rice pests. We can say that the assumptions: rice transplanting dates and intermediate hosts have an influence on reducing infection of rice stem borer; the strong period of outbreak infestation occurs on the first date of transplanting. The study could be deepened over another growing season, focusing on the rate of parasitism associated with Orseolia oryzivora due to Platygaster diplosisae and Aprostocetus procerae, on intermediate hosts, and accurate identification of observed natural enemies.

\section{Acknowledgements}

Our thanks to the INERA Rice Program for financial support; to the technicians of the INERA of la Vallée $d u$ $\mathrm{Kou}$, M. Raymond KIENOU, M. Boukary Irwaya OUEDRAOGO, M. Adama SANOU.

\section{REFERENCES}

[1] FAO, Situation alimentaire mondiale. Bulletin de la FAO sur l'offre et la demande des céréales. - Rome,Italie. p. 2, 2014.

[2] DGPER, Résultats définitifs de la campagne agricole 2012 et de la situation alimentaire et nutritionnelle. DGPER/MASA, Ouagadougou, Burkina Faso. 53p, 2013.

[3] MAHRH, Sécurité alimentaire au Burkina Faso. Le bulletin trimestriel d'information sur la sécurité alimentaire au Burkina Faso. $\mathrm{N}^{\circ} 20$ et 21. 21p, 2013.

[4] N. M. BA, D. DAKOUO, S.NACRO \& F.KARAMAGE, "Seasonal abundance of lepidopterous stem borers and diopsid fly in irrigated fields of cultivated (Oryza sativa L.) and wild rice (O. longistaminata $\mathrm{Chev} \& \mathrm{Roehr})$ in western Burkina Faso". International Journal of Tropical Insect Science 27, 2008.

[5] S. NACRO \& J. P. NENON "Comparative study of the morphology of the ovipositor of Platygaster diplosisae (Hymenoptera: Platygasteridae) and Aprostocetus procerae (Hymenoptera: Eulophidae) two parasitoids associated with the African Rice Gall Midge, Orseolia oryzivora (Diptera": Cecidomyiidae). Hindawi Publishing Corporation, 7 p, 2009.
[6] E. A. HEINRICHS \& A. T BARRION, "Rice-feeding insects and selected naturalenemies in West Africa: Biology, Ecology, and Identification. Los Banos (Philippines)": International Rice Research Institute and Abidjan (Côte d'Ivoire): WARDA-The Africa Rice Center, 242 p 2004.

[7] N. M. BA, D. DAKOUO, S. NACRO \& F. KARAMAGE, "Seasonal abundance of lepidopterous stem borers and diopsid fly in irrigated fields of cultivated (Oryza sativa L.) and wild rice (O. longistaminata $\mathrm{Chev} \& \mathrm{Roehr})$ in western Burkina Faso". International Journal of Tropical Entomology, vol. 28, № 1, pp. 30-36, 2007

[8] R. M.KUMAR, K.SUREKHA, C. PADMAVATHI, L.V. S RAO, LATHA, P.C. PRASAD M.S, V. R. BABU, A.S RAMPRASAD, O.P. RUPELA, V.V. GOUD, N. SOMASHEKAR, S. RAVICHANDRAN, \& B.C.VIRAKTAMATH, "Research experiences on System of Rice Intensification and future directions". Journal of Rice Research 2(2): p 61-74, 2009.

[9] P. MURALIDHARAN \& I. P. PASALU, “Assessments of crop losses in rice ecosystems due stem borer damage (Lepidoptera: Pyralidae)". Crop protection, 25: 409-417, 2005.

[10] D. DAKOUO, S. NACRO \& B. BACYE, "Mise au point d'un système de lutte rationnelle contre les insectes ravageurs sur les périmètres rizicoles irrigués au Burkina Faso". Insect Science and Its Application 12: 565-570, 1991.

[11] D. OUATTARA, D. DAKOUO \& S. NACRO, "La lutte intégrée contre les principaux insectes ravageurs en riziculture irriguée à KarFig.uela”. Sciences et techniques, Sciences naturelles et agronomie, Spécial hors-série $n^{\circ} 2$. pp $9-24,2014$.

[12] D. DAKOUO, S. NACRO \& M. SIE, "Evolution saisonnière des infestations de la cécidomyie du riz, Orseolia oryzivora H. et G. (Diptera, Cecidomyiidae) dans le Sud-Ouest du Burkina Faso ké, Côte d'Ivoire, pp 20-26, 2007.

[13] K. SAMA, S. NACRO, \& D. DAKOUO, "Effect of transplanting period on the population dynamics, parasitism and damage of lepidopteran rice stem borers in irrigated rice scheme of Kou Valley, Burkina Faso". International Journal of Tropical Insect Science Vol. 35, No. 1, Icipe. pp. 11-16, 2015.

[14] ARRAUDEAU, "Le riz irrigué. Tome I et Tome II. Centre technique de coopération agricole et rurale (C.T.A) ; Agence de Coopération Culturelle et Technique (ACCT) ". Edition Maisonneuve et Larose; Paris, France. pp 323-325, 1998.

[15] S. A. BARRO, "Etude de l'importance économique de la cécidomyie africaine du riz, Orseolia oryzivora H. \& G. sur la plaine rizicole de Boulbi". Mémoire de fin d'études, option Agronomie, Institut du Développement Rural, Université polytechnique de Bobo-Dioulasso, Burkina Faso, 62p, 2004.

[16] ADRAO, "Une petite mouche à gros problèmes: la cécidomyie africaine des galles du riz", Rapport annuel, Bouaké, Côte d'Ivoire, pp 20-26, 2007.

[17] S. NACRO, D. DAKOUO \& E.A. HEINRICHS, "Population dynamics, host plant damage and parasitism associated with the African rice gall midge in southern 
Burkina Faso". Insect Sci. Applic, 16 (3 / 4), 251-257, 1995.

[18] H. M. TANKOANO \& S. NACRO, "Effect of Transplanting Period on the Population Dynamics and Parasitism of the African Rice Gall Midge Orseolia Oryzivora Harris \& Gagné (Diptera: Cecidomyiidae) Under Irrigated Conditions in Boulbi, Central Burkina Faso". International Journal of Agriculture Innovations and Research Volume 3, Issue 4, ISSN pp 2319-1473, 2015.

[19] N. M. BA, "Cycle annuel de la Cécidomyie africaine du riz, Orseolia oryzivora Harris et Gagné (Diptera: Cecidomyiidae) en relation avec ses plantes hôtes ses parasitoïdes et certaines pratiques culturales au sud-Ouest du Burkina Faso". Thèse en Science biologiques Appliquées, option: Biologie et Ecologie Animales. Unité de formation et de recherche en science de la vie et de la terre (UFR/SVT). Université de Ouagadougou; 121p, 2003.

[20] T. HIDAKA, N.WIDIARTA, "Strategy of rice gall midge control." JARQ 20(1): pp 20-24, 1986.

[21] C. T. WILLIAMS, K. M. HARRIS, M. N. UKWUNGWU, S. NACRO, D. DAKOUO, F. E. NWILENE, B. N. SINGH \& O. OKHIDIEVBIE, "African Rice Gall Midge. Research Guide. WARDA/ADRAO”, Bouaké, Côte d'Ivoire \& CABI, Slough, UK, 28 p, 2000.

[22] M. SOUOBOU, S. NACRO, \& D. OUATTARA, Natural enemies associated with rice stemborers in the Kou Valley, Burkina Faso. International" Journal of Tropical Insect Science Vol. 35, No. 4, pp. 164-171, 2015. 